\title{
The dependence of scaling law on stoichiometry for horizontally propagating vertical chemical fronts
}

\author{
Éva Pópity-Tóth, Dezső Horváth, and Ágota Tóth* \\ Department of Physical Chemistry and Materials Science, \\ University of Szeged, Aradi vértanuk tere 1., Szeged, H-6720, Hungary
}

(Dated: July 29, 2011)

\begin{abstract}
Horizontally propagating fronts in the iodate-arsenous acid reaction are investigated experimentally in a vertically oriented Hele-Shaw cell by varying the height of liquid layer for various stoichiometry. At the preset conditions a stable pattern develops which can be characterized by its mixing length defined as the standard deviation of the front position in the direction of propagation. The mixing length scales with the height of the reaction vessel, and although the exponent significantly changes by varying the ratio of the reactants, it has a universal value when the reaction front is thin and simple convection arises.
\end{abstract}

PACS numbers: 47.20.Bp, 47.54.-r, 47.70.Fw, 82.20.-w

${ }^{*}$ E-mail : atoth@chem.u-szeged.hu 


\section{INTRODUCTION}

Chemical reactions coupled with transport processes can be observed in our every-day's life, like dispersion of chemical pollutants in ocean or in the atmosphere or even during sedimentation of particles in the process of solidification. Furthermore the magmatic flow and volcanic eruptions, geostorage of carbon dioxide, petrol removal from the earth, or the air currents modifying daily weather also belong to this category. In all of the examples the major driving force is mass transport or heat conduction. To understand their mechanism, the investigation of hydrodynamic instabilities, especially in reactive systems, is therefore of great importance.

One of the simplest scenarios to induce macroscopic mass transport is to establish a change in chemical composition which leads to the local variation of density[1]. If the reaction is a simple bimolecular reaction, the interface separating the reactants from the product becomes distorted in the presence of convection under the gravitational field. In the course of the reaction, the reactant and the product become mixed due to convection with the separating interface continuously changing according to the stratification of density $[2,3]$. When the reaction is autocatalytic, the evolving interface - also termed chemical front - is characterized by a constant width and under appropriate conditions the developed structure can travel with constant velocity and shape[4-9]. At the same time the density difference between the two sides of the interface sustained by the chemical reaction also remains constant. There are two model front reactions where hydrodynamic instabilities have been characterized in details: the iodate-arsenous acid (IAA) reaction[10], where the products are less dense than the reactants, and the reaction is slightly exothermic[11-16]. Thus, both the solutal and the thermal density changes are negative[17] leading to enhanced convection when both contributions are significant. The second model reaction is the chlorite oxidation of tetrathionate[18], (CT reaction) which results in a denser product solution, and hence in increasing density under isothermal conditions[19-21]. This reaction is also exothermic yielding a negative thermal effect. Overall the density contributions have opposite signs giving rise to a variety of interesting patterns when the magnitude of the changes are comparable[8, 22]. Since the effects are competing, there have been cases where it is of great importance to separate them and investigate the individual contribution. The thermal density change in aqueous solutions have successfully been eliminated by considering the 
expected temperature rise and then carrying out the experiments around $4{ }^{\circ} \mathrm{C}$, where the density of water has a maximum. The evolution and further development of the patterns have been characterized both numerically and experimentally for the two example cases.

It has been shown numerically by varying the size of the system that there is a scaling law between the characteristic mixing length of the interface and the width of the liquid layer[23, 24]. When the front propagates parallel to the gravity field, the mixing length is proportional to the width determined by the container. The experiments carried out in the CT reaction have proved the numerical prediction for certain chemical compositions[9]. In systems where the fronts travel perpendicular to the gravity field the numerically predicted proportionality is different from that obtained in experiments: Rongy et al.[24] have shown that the mixing length scales to the square of the solution height. Experimentally by varying the height of the reaction vessel, however, it has been shown in the CT system that the scaling law does not match the numerical prediction when the height of the liquid is in the centimeter range (a magnitude greater than in the calculations) [22, 25]. In the absence of thermal effects for a $1 \mathrm{~mm}$ thin slab, the experimentally determined exponent of $1.19 \pm 0.04$ in the scaling law has been found to be independent of the chemical composition at constant ratio of reactants[25] The effect of solution thickness on the CT system has also been investigated thoroughly[22]. In thick solutions, the solutal and thermal densities become comparable and a continuously changing "oscillating" front develops[22, 26]. Eliminating the thermal contribution of the total density change by carrying out the experiments at $3{ }^{\circ} \mathrm{C}$ ambient temperature[27], we have been able to determine the self-similar properties even for $3 \mathrm{~mm}$ thick solutions. The exponents are $1.34 \pm 0.09$ and $1.31 \pm 0.08$ on increasing the solution thickness to 2 and $3 \mathrm{~mm}$, respectively. These numbers are significantly different than the numerically predicted value of 2[24]. Recently Bou Malham et al. [28] have suggested that the normalized effective diffusion coefficient versus aspect ratio-defined as solution height over solution thickness - is a saturation-like function if the width of the front is negligible, i.e., the eikonal approximation holds. With this function both the square and the experimentally observed power dependence can be explained[28, 29]. The larger exponent is valid for small solution height when the drag against the fluid flow imposed by the boundary is dominant. This effect is significantly smaller for the heights characteristic to the experimental systems yielding a smaller exponent.

In this work we are going to carry out the experimental characterization of the long 
time behavior of horizontally propagating vertical chemical fronts developed in Hele-Shaw cells[30]. Scaling laws of the stable patterns will be determined for various chemical compositions and temperature to quantitatively describe the self-similar properties of the iodatearsenous acid reaction, which represents a prototype different from the previously studied chlorite-tetrathionate reaction. Two main reactions comprise the mechanism of IAA reaction[10]:

$$
\begin{aligned}
\mathrm{IO}_{3}^{-}+5 \mathrm{I}^{-}+6 \mathrm{H}^{+} & =3 \mathrm{I}_{2}+3 \mathrm{H}_{2} \mathrm{O} \\
\mathrm{H}_{3} \mathrm{AsO}_{3}+\mathrm{I}_{2}+\mathrm{H}_{2} \mathrm{O} & =2 \mathrm{I}^{-}+\mathrm{H}_{2} \mathrm{AsO}_{4}^{-}+3 \mathrm{H}^{+}
\end{aligned}
$$

leading to two distinct stoichiometries for the net reaction, depending on the initial reactant ratio. For $\left[\mathrm{H}_{3} \mathrm{AsO}_{3}\right]_{0}>3\left[\mathrm{IO}_{3}^{-}\right]_{0}$ iodide ion is the product according to

$$
\mathrm{IO}_{3}^{-}+3 \mathrm{H}_{3} \mathrm{AsO}_{3}=\mathrm{I}^{-}+3 \mathrm{H}_{2} \mathrm{AsO}_{4}^{-}+3 \mathrm{H}^{+}
$$

while for $\left[\mathrm{H}_{3} \mathrm{AsO}_{3}\right]_{0}<5 / 2\left[\mathrm{IO}_{3}^{-}\right]_{0}$ iodine is produced as

$$
2 \mathrm{IO}_{3}^{-}+5 \mathrm{H}_{3} \mathrm{AsO}_{3}=\mathrm{I}_{2}+5 \mathrm{H}_{2} \mathrm{AsO}_{4}^{-}+\mathrm{H}_{2} \mathrm{O}+3 \mathrm{H}^{+}
$$

The range of reactant ratio between 3 and $5 / 2$ can be further divided by considering the $\mathrm{I}_{2}+\mathrm{I}^{-}=\mathrm{I}_{3}^{-}$equilibrium, which allows a third stoichiometry with triiodide ion as its product. Therefore below reactant ratio of $8 / 3$ iodine and triiodide ion, while above that triiodide and iodide ions are produced in various amount. These changes in the composition of the product will lead to varying net density change associated with the reaction fronts produced in the experiments.

\section{EXPERIMENTAL}

We used reagent-grade chemicals (Sigma, Aldrich, Reanal) throughout the experiments. The solutions, with composition summarized in Table 1, were mixed at room temperature and injected into a $42 \mathrm{~cm}$ long, $3 \mathrm{~mm}$ thin reaction vessel with two $8 \mathrm{~mm}$ thick Plexiglas walls and various heights of $1,1.5,2,2.5,3$, and $4 \mathrm{~cm}$. The scheme of the reaction vessel is shown in Fig. 1. Vertical fronts were initiated electrochemically by applying a $3 \mathrm{~V}$ potential difference between two $\mathrm{Pt}$ wires $(0.25 \mathrm{~mm}$ in diameter). We monitored the traveling fronts through an appropriate cut-off filter $\left(\lambda_{m}=468 \pm 10 \mathrm{~nm}\right)$ by a monochrome CCD camera. 
The frames were digitized in $0.6-5 \mathrm{~s}$ intervals. The solution densities were measured with an AP Paar DMA 58 digital densitymeter within $10^{-5} \mathrm{~g} / \mathrm{cm}^{3}$ precision. Temperature profiles were obtained by utilizing a type $\mathrm{J}$ thermocouple.

Front position was defined as the point of inflection in the gray scale values along the direction of propagation (x coordinate). The mean front position was determined by averaging the front positions perpendicular to the direction of the propagation (z coordinate). We calculated the mixing length and the temporal average of the stable front profiles to characterize the final geometry. The mixing length is given as the standard deviation of the front position. The temporal average was the time average of the mixing length for a selected interval, during which the front maintains a constant shape. Within this time span, generally one hundred profiles were evaluated and averaged resulting in an error for the mixing length on the scale of the spatial resolution of the digitized image, which ensures that a stable profile is observed. Each experiment was repeated two to three times and the reproducibility in the mixing length was less than $5 \%$. For each experiment the translation of the average front position provided the velocity of propagation.

\section{RESULTS \& DISCUSSION}

A reactant ratio of 3.9 was arbitrarily selected as the first initial composition where the final product is iodide and the intermediate iodine production is minimal. Figure 2(a) depicts the stable front shape developed. The thin black/dark zone represents the front which corroborates the prediction that the zone where iodine appears as an intermediate is very narrow. The product solution has smaller density than the reactant solution (see Table II), yielding an interface distorted by the single convection roll arising in the vertical solution layer for fronts propagating horizontally (from left to right in Figure 2(a)). The mixing length is determined to be $2.22 \pm 0.02 \mathrm{~cm}$ - according to its definition about a quarter of the maximum extent of the front in the direction of propagation-, which increases on increasing the solution height. By fitting a power law on the data shown in Fig. 2(b), we have obtained the following equation

$$
L_{m} / \mathrm{cm}=(2.28 \pm 0.04)\left(L_{z} / \mathrm{cm}\right)^{1.33 \pm 0.02} .
$$


The exponent, within the experimental error, matches the exponent (1.31 \pm 0.08$)$ [22] determined for the chlorite-tetrathionate reaction with experimental conditions at which chlorite is in slight excess and as a result the width of the front, measured in the direction of propagation, is narrow. This then also supports the result of Jarrige et al. [29] who have studied the effect of tilting the reaction vessel on the front velocity, and concluded that for fronts of small width, where the eikonal approximation holds, the self-similar properties like scaling laws for velocity or mixing length are anticipated to be independent of reaction kinetics.

The properties of chemical fronts in the iodate-arsenous acid reaction change significantly on varying the stoichiometry of the system. We therefore carried out experiments by decreasing the reactant ratio to 2.8 where arsenous acid becomes the stoichiometrically limiting species and the final product is a mixture of iodide and iodine, mainly present in the triiodide form. Under these compositions, the amount of arsenous acid is less in the reactant mixture and hence the density of reactants is lowered but the products remain less dense than the reactants (see Table II). Therefore, for a horizontally propagating vertical chemical front, the products will tend to rise above the reactants as illustrated in Fig. 3. After a-typically 200-300 s-transition period, an asymmetric structure develops which will travel with constant shape and velocity. Figure 4 illustrates that the shape is similar in all cases and the mixing length increases on increasing the height of the solution layer. To determine the scaling law for the ratios of $\left[\mathrm{H}_{3} \mathrm{AsO}_{3}\right]_{0} /\left[\mathrm{KIO}_{3}\right]_{0}=2.8$, we fitted a power law on the data shown in Fig. 3. The obtained equation is

$$
L_{m} / \mathrm{cm}=(2.2 \pm 0.1)\left(L_{z} / \mathrm{cm}\right)^{1.17 \pm 0.06}
$$

The smaller exponent indicates that the eikonal approximation is now less accurate. With iodate in stoichiometric excess, the rate of the reaction between iodine and arsenous acid also contributes to the net reaction rate and the system cannot entirely be considered as a single-step autocatalytic process converting the reactants into products. At the reaction zone more intermediate species accumulates effectively widening the zone itself. The density change across the reaction front hence will not be as abrupt.

At this composition heat effects may be significant therefore temperature profiles were also recorded. The maximum temperature rise of $0.5 \mathrm{~K}$ suggests that the thermal contribution to the overall density change may be considerable at room temperature, however it can be effectively eliminated by carrying out the reaction at $4^{\circ} \mathrm{C}$, as shown previously for downward 
propagating fronts of the CT reaction[27, 31]. The front geometry at this temperature is similar but the mixing length is significantly smaller in agreement with the smaller density decrease because the parallel thermal contribution is now absent. Upon increasing the liquid height, the mixing length increases analogously to the one observed at room temperature (see triangles in Fig. 3). The appropriate fitting leads to the equation of

$$
L_{m} / \mathrm{cm}=(1.80 \pm 0.08)\left(L_{z} / \mathrm{cm}\right)^{1.23 \pm 0.05} .
$$

for $\left[\mathrm{H}_{3} \mathrm{AsO}_{3}\right] /\left[\mathrm{KIO}_{3}\right]=2.8$ at $4{ }^{\circ} \mathrm{C}$. The power-law dependence is valid at low temperature and the exponent within the experimental error is equal to that determined at room temperature. This is in accordance with the fact that no qualitative change in the reaction mechanism occurs by lowering the temperature at constant reactant ratio. The convection roll at the reaction front is driven by a smaller difference in density across the front due to the absence of thermal contribution, resulting in a smaller constant in the equation above.

If we consider the system with even lower reactant ratio, the amount of pure iodine increases and the density change is also affected. We choose the ratio of $\left[\mathrm{H}_{3} \mathrm{AsO}_{3}\right] /\left[\mathrm{KIO}_{3}\right]=2.6$ as an example where the reactant density is smaller since the arsenous acid content is lower compared to the previous compositions. The density decrease is more pronounced (cf. Table II), since the concentration of free iodine produced is greater. We have to be careful in interpreting the final density because the product is supersaturated in iodine, and hence it slowly phase separates. The effective density difference in the vicinity of the reaction front is anticipated to be smaller and, in fact, by comparing Figs. 5 and 2, one clearly sees that the mixing length is significantly lower. The temperature increase is in the same range as that observed for the reactant ratio of 2.8, therefore the scaling law is determined at room temperature only. The curve is different which is shown by the result of the fitting as well (see Fig. 6), since the equation is

$$
L_{m} / \mathrm{cm}=(1.39 \pm 0.09)\left(L_{z} / \mathrm{cm}\right)^{0.78 \pm 0.06} .
$$

The obtained exponent is even less than one, indicating a large deviation from the previous cases. At this ratio, the smaller concentration of arsenous acid leads to the further slowing down of its reaction with iodine and hence to the widening of the reaction front. The scaling law therefore does not reflect those obtained for simple autocatalytic model systems.

The velocity of propagation determined for the various cases is listed in Tab. III. From the data we can conclude that it is mainly determined by the autocatalytic reaction between 
iodate and iodide, since no significant change occurs when the reactant ratio is decreased. According to Bou Malham et al. [28], the velocity of propagation is proportional to $L_{m} / L_{z}$ for the parameter range of our experiments, therefore following our Eq. (5) the scaling for velocity is anticipated as $v \propto L_{z}^{0.33}$. Our results agree with this prediction as an exponent of $0.36 \pm 0.05$ is obtained for the largest iodate excess, which is best approximated by simple autocatalytic models.

In conclusion, the results reveal that a universal scaling exponent exists for mixing length with the height of liquid layer in the centimeter range. The exponent is independent of the chemistry and whether density increases or decreases in the course of the reaction as long as the reaction front is thin and no significant heat effects are present. Under these conditions, the reaction front is essentially a thin reactive interface converting the reactant into product with different density, and can by approximated with an autocatalytic model giving rise to simple convection. The universality breaks down when the width of the reaction zone increases by changing the stoichiometry of the iodate-arsenous reaction. The density change is then not as steep as in case of large arsenous acid excess, since processes consecutive the autocatalytic step become significant.

\section{Acknowledgments}

This work was financially supported by the Hungarian Scientific Research Fund (OTKA K72365) and the European Space Agency (ESTEC 4000102255/11/NL/KML). 
[1] I.R. Epstein and J.A. Pojman, An Introduction to Nonlinear Dynamics: Oscillations, Waves, Patterns, and Chaos, Oxford University Press, Oxford, 1998.

[2] A. Zalts, C. El Hasi, D. Rubio, A. Ureña, A D’Onofrio, Phys. Rev. E 77, 015304(R) (2008).

[3] C. Almarcha, P.M.J. Trevelyan, P. Grosfils, A. De Wit, Phys. Rev. Lett. 104, 044501 (2010).

[4] J. Huang, D. A. Vasquez, B. F. Edwards and P. Kolodner, Phys. Rev. E 48, 4378 (1993).

[5] D. A. Vasquez, J. W. Wilder and B. F. Edwards, J. Chem. Phys. 104, 9926 (1996).

[6] A. De Wit, Phys. Fluids 16, 163 (2004).

[7] T. Bánsági, Jr., D. Horváth and Á. Tóth, J. Chem. Phys. 121, 11912 (2004).

[8] T. Bánsági, Jr., D. Horváth, Á. Tóth, J. Yang, S. Kalliadasis and A. De Wit, Phys. Rev. E 68, 055301 (2003).

[9] T. Tóth, D. Horváth and Á. Tóth, J. Chem. Phys. 128, 144509 (2008).

[10] A. Hanna, A. Saul, K. Showalter, J. Am. Chem. Soc. 104, 3838 (1982).

[11] J.A. Pojman and I.R. Epstein, J. Phys. Chem. 94, 4966 (1990).

[12] M. Böckmann and S. C. Müller, Phys. Rev. Lett. 85, 2506 (2000).

[13] A. De Wit, Phys. Rev. Lett. 87, 054502 (2001).

[14] S. Kalliadasis, J. Yang and A. De Wit, Phys. Fluids 16, 1395 (2004).

[15] L. Sebestiková, J.D. D’Hernoncourt, M.J.B. Hauser, S.C. Müller and A. De Wit, Phys. Rev. E 75, 026309 (2007).

[16] M.C. Rogers, M.D. Mantle, A.J. Sederman, S.W. Morris, Phys. Rev. E 77, 026105 (2008).

[17] J.A. Pojman, I.R. Epstein, T. McManus and K. Showalter, J. Phys. Chem. 95, 1299 (1991).

[18] L. Szirovicza, I. Nagypál, E. Boga, J. Am. Chem. Soc. 111, 2842 (1990).

[19] I. Nagypál, Gy. Bazsa and I.R. Epstein, J. Am. Chem. Soc. 108, 3635 (1986).

[20] D. Horváth, T. Bánsági, Jr., Á. Tóth, J. Chem. Phys. 117, 4399 (2002).

[21] J. Yang, A. D’Onofrio, S. Kalliadasis and A. De Wit, J. Chem. Phys. 117, 9395 (2002).

[22] L. Rongy, G. Schuszter, Z. Sinkó, T. Tóth, D. Horváth, Á. Tóth, A. De Wit, Chaos 19, 023110 (2009).

[23] D. Lima, A. D’Onofrio and A. De Wit, J. Chem. Phys. 124, 014509 (2006).

[24] L. Rongy, N. Goyal, E. Meiburg and A. De Wit, J. Chem. Phys. 127, 144710 (2007).

[25] G. Schuszter, T. Tóth, D. Horváth and Á. Tóth, Phys. Rev. E 79, 016216 (2009). 
[26] T. Bánsági, Jr., D. Horváth and Á. Tóth, Chem. Phys. Lett. 384, 153 (2004).

[27] T. Tóth, D. Horváth and Á. Tóth, Chem. Phys. Lett. 442, 289 (2007).

[28] I. Bou Malham, N. Jarrige, J. Martin, N. Rakotomalala, L. Talon, D. Salin, J. Chem. Phys. 133, 244505 (2010).

[29] N. Jarrige, I. Bou Malham, J. Martin, N. Rakotomalala, D. Salin, L. Talon, Phys. Rev. E 81, $066311(2010)$.

[30] H.S. Hele-Shaw, Nature 58, 34 (1898).

[31] G.G. Casado, L. Tofaletti, D. Müller and A. D'Onofrio, J. Chem. Phys. 126, 114502 (2007). 
TABLE I: Composition of reactant solution

\begin{tabular}{ll}
{$\left[\mathrm{KIO}_{3}\right] / \mathrm{M}$} & 0.0129 \\
{$\left[\mathrm{H}_{3} \mathrm{AsO}_{3}\right] / \mathrm{mM}$} & $0.033-0.039$ \\
$\mathrm{pH}$ & 7.0 \\
\hline
\end{tabular}

TABLE II: Density of the solutions.

\begin{tabular}{ccrrrr}
\hline$\left[\mathrm{H}_{3} \mathrm{AsO}_{3}\right]_{0} /\left[\mathrm{KIO}_{3}\right]_{0} \mathrm{~T} /{ }^{\circ} \mathrm{C}$ & \multicolumn{3}{c}{$\rho /\left(\mathrm{g} \mathrm{cm}^{-3}\right)$} \\
& & reactant & product & difference \\
\hline 3.9 & 25 & 1.00643 & 1.00620 & -0.00023 \\
2.8 & 25 & 1.00449 & 1.00429 & -0.00020 \\
$2.6^{*}$ & 25 & 1.00405 & $(1.00333)$ & $(-0.00072)$ \\
2.8 & 4 & 1.00769 & 1.00754 & -0.00015
\end{tabular}

* At this reactant ratio the product solution is supersaturated in iodine and phase separates slowly. The measured product density and hence the density difference can only be considered as crude estimates and therefore are in parentheses.

TABLE III: Velocity of propagation in $\mathrm{cm} / \mathrm{s}$ at $\mathrm{T}=25^{\circ} \mathrm{C}$

\begin{tabular}{c|cccc}
\hline & \multicolumn{4}{|c}{ Height of the container $\left(L_{y} / \mathrm{cm}\right)$} \\
{$\left[\mathrm{H}_{3} \mathrm{AsO}_{3}\right]_{0} /\left[\mathrm{KIO}_{3}\right]_{0}$} & 1 & 1.5 & 2 & 2.5 \\
\hline 3.9 & $0.0313 \pm 0.0016$ & $0.0350 \pm 0.0003$ & $0.0382 \pm 0.0024$ & $0.0438 \pm 0.0004$ \\
2.8 & $0.0289 \pm 0.0002$ & $0.0347 \pm 0.0038$ & $0.0356 \pm 0.0010$ & $0.0391 \pm 0.0022$ \\
2.6 & $0.0282 \pm 0.0017$ & $0.0381 \pm 0.0005$ & $0.0389 \pm 0.0005$ & $0.0494 \pm 0.0004$ \\
\hline
\end{tabular}


Fig. 1 Scheme of the Hele-Shaw cell.

Fig. 2 Image of a front propagating from left to right with constant shape at $25^{\circ} \mathrm{C}$ for solution composition with $\left[\mathrm{H}_{3} \mathrm{AsO}_{3}\right] /\left[\mathrm{KIO}_{3}\right]=3.9$ ratio at $1 \mathrm{~cm}$ solution height (a). Darker region represents the chemical front where the intermediate iodine is apparent. The mixing length $L_{m}$ as a function of solution height $L_{z}$ for this composition (b). The solid line shows the power fitting for the experimental data.

Fig. 3 Images of fronts propagating form left to right with constant shape at $25{ }^{\circ} \mathrm{C}$ for solution composition with $\left[\mathrm{H}_{3} \mathrm{AsO}_{3}\right] /\left[\mathrm{KIO}_{3}\right]=2.8$ ratio at $1 \mathrm{~cm}$ (a) and $1.5 \mathrm{~cm}$ (b) solution height. Dark regions represent the less dense product solution and light ones the dense reactant.

Fig. 4 The mixing length $L_{m}$ as a function of solution height $L_{z}$ at $25^{\circ} \mathrm{C}(\bullet)$ and $4{ }^{\circ} \mathrm{C}$ (ム) with $\left[\mathrm{H}_{3} \mathrm{AsO}_{3}\right] /\left[\mathrm{KIO}_{3}\right]=2.8$ ratio. The solid line shows the fitting at $25^{\circ} \mathrm{C}$ and dashed lines at $4{ }^{\circ} \mathrm{C}$.

Fig. 5 Images of fronts propagating form left to right with constant shape at $25^{\circ} \mathrm{C}$ for solution composition with $\left[\mathrm{H}_{3} \mathrm{AsO}_{3}\right] /\left[\mathrm{KIO}_{3}\right]=2.6$ ratio at $1 \mathrm{~cm}(\mathrm{a})$ and $2.5 \mathrm{~cm}$ (b) solution height. Dark regions represent the less dense product solution and light ones the dense reactant.

Fig. 6 The mixing length $L_{m}$ as a function of solution height $L_{z}$ at room temperature with $\left[\mathrm{H}_{3} \mathrm{AsO}_{3}\right] /\left[\mathrm{KIO}_{3}\right]=2.6$ ratio. The solid line shows the fitting for the experimental data. 


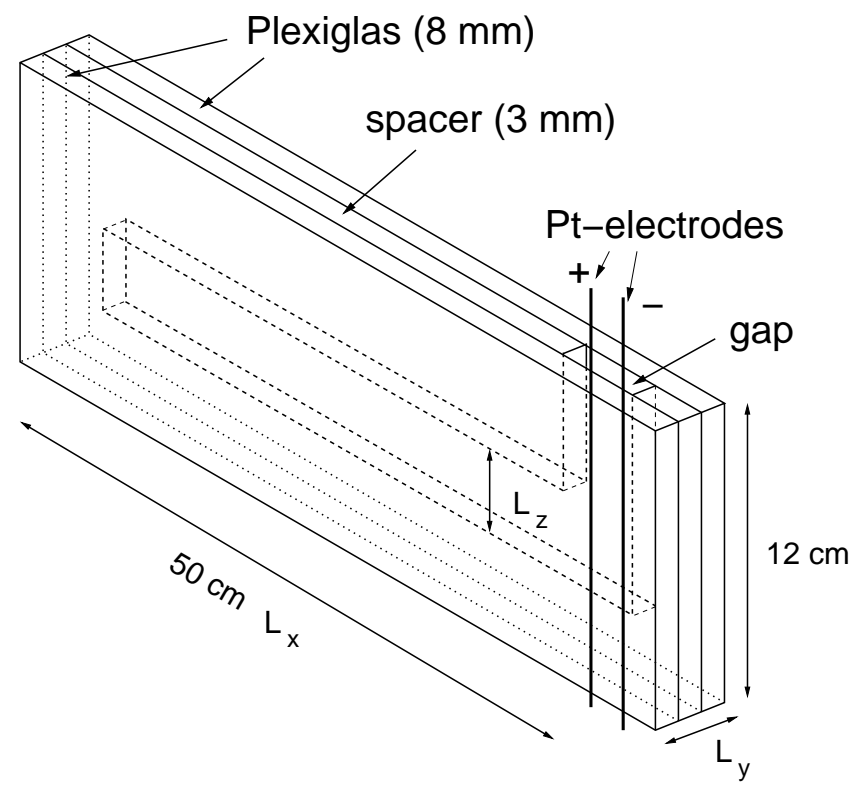

FIG. 1: É. Pópity-Tóth ... Phys. Rev. E 
(a)

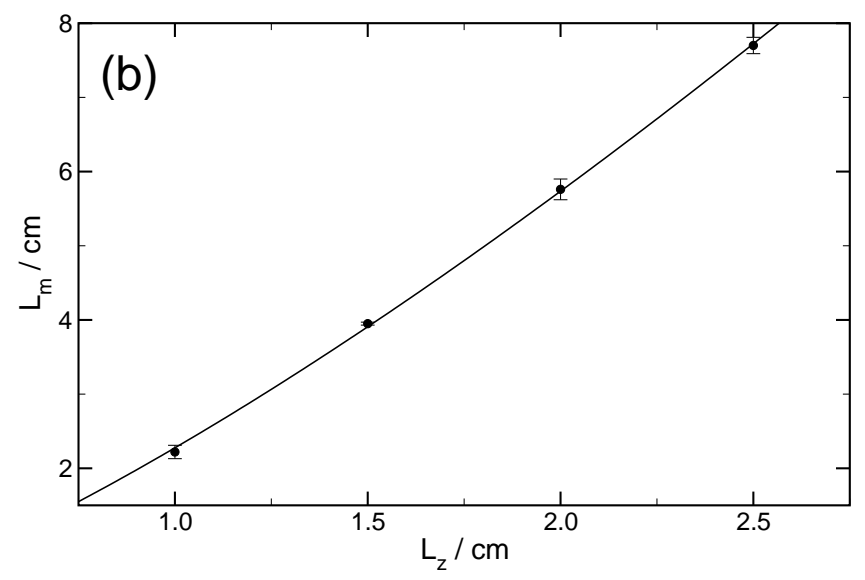

FIG. 2: É. Pópity-Tóth ... Phys. Rev. E 
(a)

(b)

FIG. 3: É. Pópity-Tóth ... Phys. Rev. E 


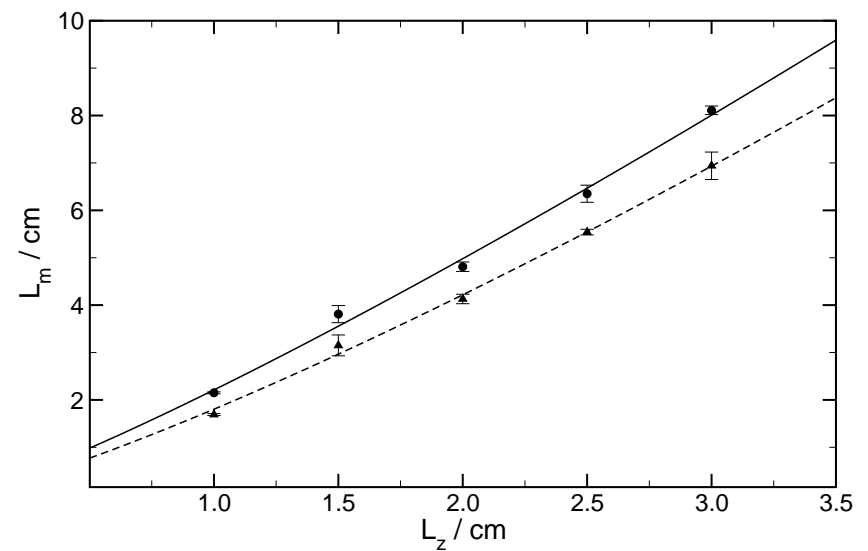

FIG. 4: É. Pópity-Tóth ... Phys. Rev. E 


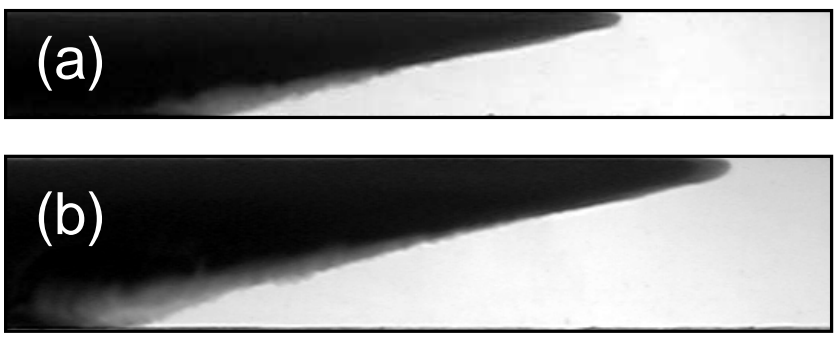

FIG. 5: É. Pópity-Tóth ... Phys. Rev. E 


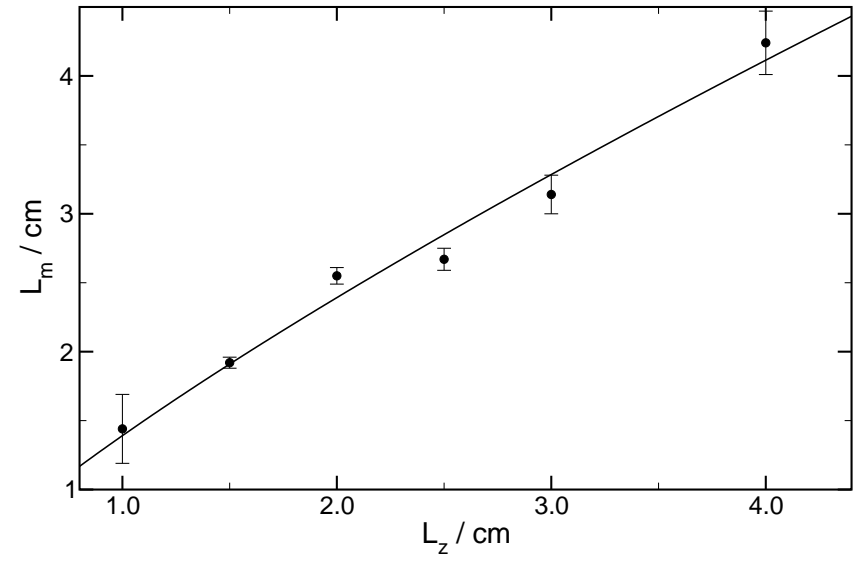

FIG. 6: É. Pópity-Tóth ... Phys. Rev. E 